\title{
$\mathrm{Nd} / \mathrm{Cr}: Y A G$ 媒質における蛍光と反転分布形成の理論的解析
}

\author{
椿本 孝治, 吉田 英次 \\ 大阪大学レーザーエネルギー学研究センター（５565-0871 大阪府吹田市山田丘2-6）
}

\section{Theoretical Analysis of Fluorescence and Population Inversion in Nd/Cr:YAG Medium}

Koji TSUBAKIMOTO and Hidetsugu YOSHIDA

Institute of Laser Engineering, Osaka University, 2-6 Yamadaoka, Suita, Osaka 565-0871

(Received May 14, 2009)

\begin{abstract}
The Nd/Cr:YAG medium is very useful for the flash lamp or sunlight pumped lasers. Theoretical analysis demonstrates that the fluorescence lifetime of the $\mathrm{Nd}$ ions depends on the ratio of the population inversion of the $\mathrm{Cr}$ and $\mathrm{Nd}$ ions. The ratio of population inversion remarkably changes due to such factors as the pumping rate, the pumping time, and the dopant concentration. Therefore measuring the effective lifetime of $\mathrm{Nd}$ ions is difficult. The benefit of the $\mathrm{Cr}$ ions may not appear soon after the start of pumping until short period of the lifetime of the $\mathrm{Nd}$ ions. When the medium is pumped by the short pulse at the absorbed wavelength of the $\mathrm{Cr}$ ions, the gain peak is delayed from the end edge of the pump light. The energy transfer rate to the $\mathrm{Nd}$ ions from the $\mathrm{Cr}$ ions is a crucial parameter. We suggest a method for calculating the transfer rate from two kinds of fluorescence.
\end{abstract}

Key Words: Nd/Cr:YAG, Theoretical analysis, Fluorescence lifetime, Population inversion, Rate equation

1.はじめに

Nd:YAGレーザー媒質は, 高い誘導放出断面積や熱伝 導性などにより，多数のレーザー装置に用いられてい る。近年では, 多結晶性セラミックスの登場で, $\mathrm{Nd}$ : YAGを基本とした複合体の生成やNd添加量の増加, 共 添加物の制御などにより, 利得の上昇や, レーザー効率 の改善といった改良がなされている。なかでも， $\mathrm{Cr}$ を共 添加したNd:YAGセラミックス ${ }^{1)}$ は, $\mathrm{Cr}^{3+}$ から $\mathrm{Nd}^{3+}$ のエ ネルギー移譲を利用することで, $\mathrm{Cr}$ の広い吸収帯を活用 できることから，フラッシュランプや太陽光といった広 帯域励起光を使う場面において, 非常に有用な材料と なっている ${ }^{2-9)}$.

$\mathrm{Nd} / \mathrm{Cr}: \mathrm{YAG}$ 媒質に対する理論的なアプローチは佐伯 $ら^{10)}$ によってなされているが, 彼らの解析は定常近似に よるものであり, 蛍光の発光特性や反転分布の形成過程 についてはなんら議論されていない.

本論文では， Nd/Cr:YAGといった共添加元素からレー ザー遷移元素へエネルギーの移譲が発生するような媒質 における励起, 発光特性をレート方程式を用いて解析し た結果について報告する。

\section{2. 連続励起における反転分布形成}

Fig. 1にNd/Cr:YAG媒質のエネルギー準位を示す ${ }^{11)}$.
$\mathrm{Cr}^{3+}$ は, 青色領域 $\left({ }^{4} \mathrm{~T}_{1}\right)$ と緑色領域 $\left({ }^{4} \mathrm{~T}_{2}\right)$ に大きな吸収を 持っている。これら2つの準位から上準位 $\left({ }^{2} \mathrm{E}\right)$ に熱的に

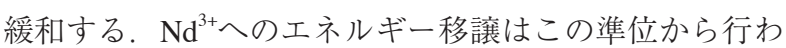
れる。 エネルギー準位関係からレート方程式を導くと次 式が得られる。

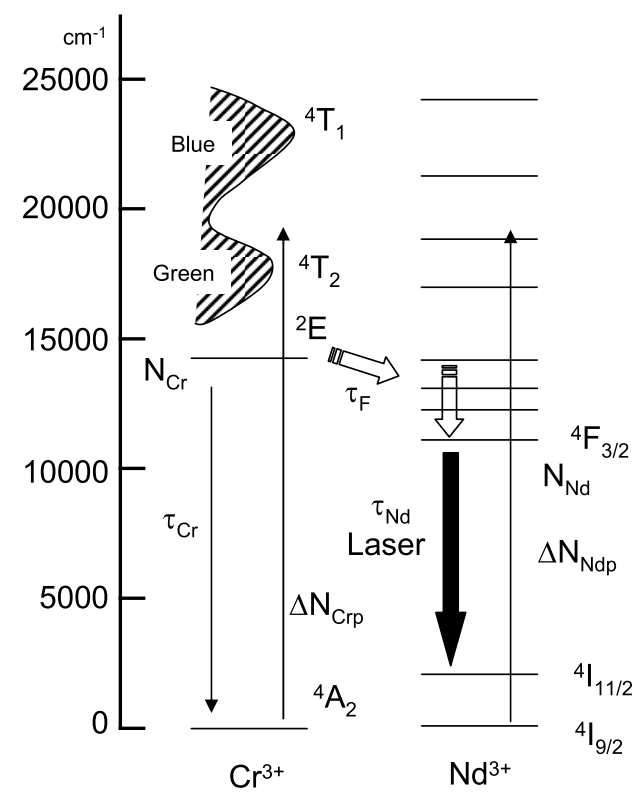

Fig. 1 Energy levels of $\mathrm{Cr}^{3+}$ and $\mathrm{Nd}^{3+}$ co-doped YAG medium. 


$$
\left\{\begin{array}{l}
\frac{d N_{\mathrm{Nd}}}{d t}=\frac{N_{\mathrm{Cr}}}{\tau_{\mathrm{F}}}-\frac{N_{\mathrm{Nd}}}{\tau_{\mathrm{Nd}}}+\Delta N_{\mathrm{Ndp}} \\
\frac{d N_{\mathrm{Cr}}}{d t}=-\frac{N_{\mathrm{Cr}}}{\tau_{\mathrm{F}}}-\frac{N_{\mathrm{Cr}}}{\tau_{\mathrm{Cr}}}+\Delta N_{\mathrm{Crp}}
\end{array}\right.
$$

ここで， $N_{\mathrm{Nd}}$ および $N_{\mathrm{Cr}}$ はそれぞれレーザー上準位におけ る粒子数密度, $\tau_{\mathrm{Nd}}, \tau_{\mathrm{Cr}}$ はNd, $\mathrm{Cr}$ のレーザー上準位から

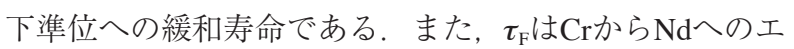
ネルギー移譲の寿命である。 $\Delta N_{\mathrm{Ndp}}, \Delta N_{\mathrm{Crp}}$ はそれぞれの 単位時間あたりに励起される数密度 (今後, 励起レート と呼ぶ)を表している。式(1)において，励起している間 は励起レートが時間によらず一定であると仮定する。こ の仮定は, 矩形パルスによる励起や一定值での連続励起 に相当する。この条件で式(1)を解くと,

$$
\begin{aligned}
& \tau_{\mathrm{Nd}} \neq \tau_{\mathrm{Cr}}^{\prime} \text { のとき } \\
& \begin{aligned}
N_{\mathrm{Nd}}= & A_{1}\left\{1-\exp \left(-\frac{t}{\tau_{\mathrm{Nd}}}\right)\right\} \\
& +B_{1}\left\{1+\frac{\tau_{\mathrm{Nd}}}{\tau_{\mathrm{Cr}}^{\prime}-\tau_{\mathrm{Nd}}} \exp \left(-\frac{t}{\tau_{\mathrm{Nd}}}\right)\right. \\
& \left.-\frac{\tau_{\mathrm{Cr}}^{\prime}}{\tau_{\mathrm{Cr}}^{\prime}-\tau_{\mathrm{Nd}}} \exp \left(-\frac{t}{\tau_{\mathrm{Cr}}^{\prime}}\right)\right\}
\end{aligned} \\
& \tau_{\mathrm{Nd}}=\tau_{\mathrm{Cr}}^{\prime} \text { のとき } \\
& N_{\mathrm{Nd}}=A_{1}\left\{1-\exp \left(-\frac{t}{\tau_{\mathrm{Nd}}}\right)\right\} \\
& +B_{1}\left\{1-\exp \left(-\frac{t}{\tau_{\mathrm{Nd}}}\right)-\frac{t}{\tau_{\mathrm{Nd}}} \exp \left(-\frac{t}{\tau_{\mathrm{Nd}}}\right)\right\}
\end{aligned}
$$

となる、ただし， $\tau_{\mathrm{Cr}}^{\prime}$ はCrの実効的な寿命であり，

$$
\frac{1}{\tau_{\mathrm{Cr}}^{\prime}}=\frac{1}{\tau_{\mathrm{Cr}}}+\frac{1}{\tau_{\mathrm{F}}}
$$

で表される。また，

$$
\begin{aligned}
& A_{1}=\Delta N_{\mathrm{Ndp}} \tau_{\mathrm{Nd}} \\
& B_{1}=\Delta N_{\mathrm{Crp}} \frac{\tau_{\mathrm{Cr}}^{\prime}}{\tau_{\mathrm{F}}} \tau_{\mathrm{Nd}}
\end{aligned}
$$

である。また熱平衡状態での数密度は無視している。十 分な時間が経過した場合, つまり, 式(2), (3)に $t \rightarrow \infty$ を代入すると，

$$
N_{\mathrm{Nd}}(\infty)=\left(\Delta N_{\mathrm{Ndp}}+\Delta N_{\mathrm{Crp}} \frac{\tau_{\mathrm{Cr}}^{\prime}}{\tau_{\mathrm{F}}}\right) \tau_{\mathrm{Nd}}=A_{1}+B_{1}
$$

となる. 式(6)から, Crの共添加によって上準位数密度 が $B_{1}$ だけ増加することがわかる。 $B_{1}$ に含まれる $\tau_{\mathrm{Cr}}^{\prime} / \tau_{\mathrm{F}}$ は，Crイオンからのエネルギー移譲率を表している。

Fig. 2に式(2)より計算した数密度の時間変化の様子を示 す。ただし， $B_{1} / A_{1}$ を0から4まで変化させた， $B_{1} / A_{1}=0$ は $\mathrm{Nd}$ :YAG単独の場合に相当する。また，図の横軸はNdの 寿命で規格化している. Fig. 2 (a) は $\tau_{\mathrm{Cr}}^{\prime}=2 \tau_{\mathrm{Nd}}$ と仮定し た場合であり, Fig. $2(\mathrm{~b})$ は $\tau_{\mathrm{Cr}}^{\prime}=0.5 \tau_{\mathrm{Nd}}$ とした場合の結果 である. Fig. 2 (a), (b)ともに, Nd:YAG $\left(B_{1} / A_{1}=0\right)$ に比 べて上準位数密度が飽和するまでに要する時間が増加し
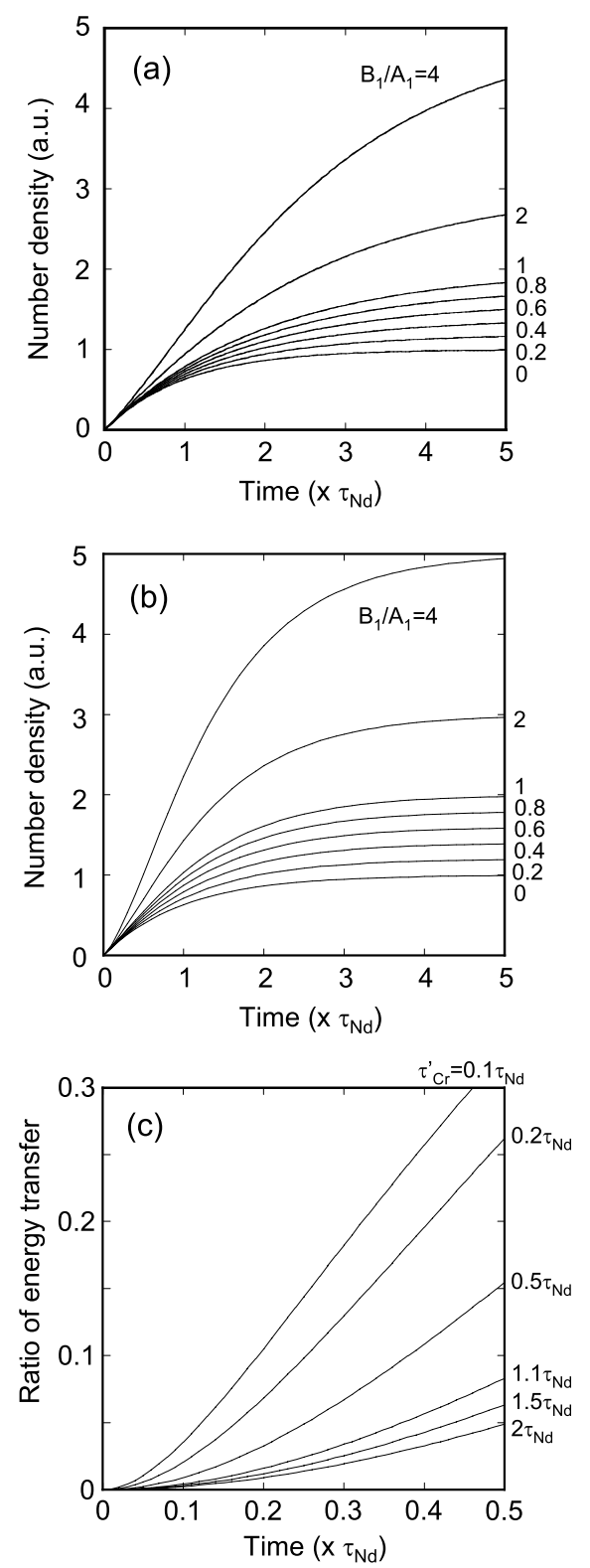

Fig. 2 (a), (b) Temporal profiles of number density at upper laser transition level of $\mathrm{Nd}^{3+}$ ion obtained by CW pumping. (c) Ratio of energy transfer form $\mathrm{Cr}^{3+}$ upper level.

ていることがわかる．特に $B_{1}$ の割合が大きくなるとその 傾向がより顕著になる。これは， $\mathrm{Nd}$ 寿命が見かけ上 長くなることを意味する. Fig. 2 (a)，（b）を比較する と，（b)の方が，つまり， $\mathrm{Cr}$ の実効的な寿命 $\tau_{\mathrm{Cr}}$ が短い方 が数密度の飽和に必要な励起時間が短い. なお, $\mathrm{Nd}$ の 蛍光寿命については3章で詳細に述べる。

Fig. 2 (c)に式 (2)右辺第2項の括弧内のみを計算した 結果を示す。ただ， $\tau_{\mathrm{Cr}}$ を $0.1 \tau_{\mathrm{Nd}}$ から $2 \tau_{\mathrm{Nd}}$ まで変化させ ている。図からわかるように，励起開始からの経過時間 が短い場合には，Crからのエネルギー移譲割合は少な

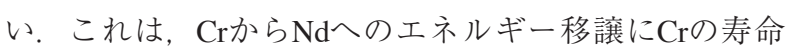
が関わっているためである。したがって，Crの寿命が短 くなれば短時間でエネルギー移譲は完了することにな る. 
次に, $\mathrm{Cr}$ の上準位にどの程度の数密度が生じるかを検 討してみる. $\mathrm{Cr}$ の上準位は, $\mathrm{Nd} ゙$ の発光, 増幅作用に 対してエネルギー供給源として働く。式(1)より, Crの 数密度は

$$
\begin{aligned}
N_{\mathrm{Cr}} & =\Delta N_{\mathrm{Crp}} \tau_{\mathrm{Cr}}^{\prime}\left\{1-\exp \left(-\frac{t}{\tau_{\mathrm{Cr}}^{\prime}}\right)\right\} \\
& =B_{1} \frac{\tau_{\mathrm{F}}}{\tau_{\mathrm{Nd}}}\left\{1-\exp \left(-\frac{t}{\tau_{\mathrm{Cr}}^{\prime}}\right)\right\}
\end{aligned}
$$

となる。式(2) および式(7)より, $\mathrm{Cr}$ と $\mathrm{Nd}$ の数密度の比 $N R=N_{\mathrm{Cr}} / N_{\mathrm{Nd}}$ を計算する. NRは $\mathrm{Nd}$ 蛍光寿命を決定する 非常に重要なパラメータとなる。このことについては次 章で詳しく述べる. $\mathrm{Cr}$ の実効的な寿命 $\tau_{\mathrm{Cr}}^{\prime}=\alpha \tau_{\mathrm{Nd}}$ とし, 工 ネルギー移譲率 $\tau_{\mathrm{Cr}}^{\prime} / \tau_{\mathrm{F}}=\gamma$ と仮定すると，NRは次式によ り与えられる。

$$
\begin{aligned}
& N R= \\
& \left(A_{1} \frac{\alpha}{\gamma}\left\{1-\exp \left(-\frac{1}{\alpha-1} \frac{t}{\tau_{\mathrm{Nd}}}\right)\right\} 1-\exp \left(-\frac{t}{\tau_{\mathrm{Nd}}}\right)\right\}+\frac{\alpha}{\alpha-1} B_{1}\left\{1-\exp \left(-\frac{1}{\alpha} \frac{t}{\tau_{\mathrm{Nd}}}\right)\right\}
\end{aligned}
$$

ただし， $\alpha \neq 1$ としている.

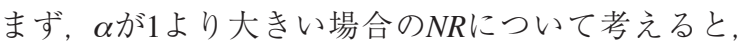
$A_{1}-B_{1} /(\alpha-1)$ が正のときには, 増加関数となり零のと きには時間に依らず一定值 $(\alpha-1) / \gamma$ に, そして, 負の ときには減少関数となる。また, 励起開始直後には, $N R$ は $B_{1} / A_{1}$ 対して大きく変化し, 特に, $A_{1}-B_{1} /(\alpha-1)$ が 負の場合, $A_{1}(\mathrm{Nd}$ の励起レート)が小さいと, 非常に大

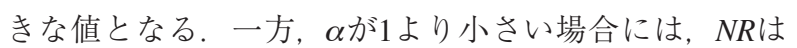
常に減少関数となる.

参考として, Fig. 3に $B_{1} / A_{1}$ を変えた場合のNRの時間変 化を示す. Fig. 3 (a) は $\alpha=2, \gamma=1, \quad$ (b) は $\alpha=0.5, \quad \gamma=1$ として計算した。縦軸は対数表示である。図から，NR は, 時間とともに減少する場合, 増加する場合および一 定の值となる場合の3種類に分類できることがわかる.

いま，十分な時間が経過した場合 $(t=\infty)$ を考えると，

$$
\lim _{t \rightarrow \infty} N R=\frac{\alpha}{\gamma+\frac{\Delta N_{\mathrm{Ndp}}}{\Delta N_{\mathrm{Crp}}}}
$$

となる. 式(9)から, 最終的に得られる数密度の比 $N R$ は, 寿命の比 $\alpha$, 移譲率 $\gamma$ およ゙励起レートの比で決ま ることがわかる。

\section{3. 蛍光特性}

式（1）において，励起レートを零にすることで蛍光の 時間依存性を予測することができる。式(1)より，

$$
\begin{aligned}
\tau_{\mathrm{Nd}} \neq \tau_{\mathrm{Cr}}^{\prime} \text { のとき, } & \\
N_{\mathrm{Nd}} & =\left(A_{2}-B_{2}\right) \exp \left(-\frac{t}{\tau_{\mathrm{Nd}}}\right)+B_{2} \exp \left(-\frac{t}{\tau_{\mathrm{Cr}}^{\prime}}\right) \\
A_{2} & =N_{\mathrm{Nd}}(0) \\
B_{2} & =\frac{\tau_{\mathrm{Cr}}^{\prime}}{\tau_{\mathrm{F}}} \frac{\tau_{\mathrm{Nd}}}{\tau_{\mathrm{Cr}}^{\prime}-\tau_{\mathrm{Nd}}} N_{\mathrm{Cr}}(0) \\
& =\frac{\gamma}{\alpha-1} N R \cdot A_{2} \\
\tau_{\mathrm{Nd}} \neq \tau_{\mathrm{Cr}}^{\prime} \text { のとき, } & \\
N_{\mathrm{Nd}} & =\exp \left(-\frac{t}{\tau_{\mathrm{Nd}}}\right)\left\{N_{\mathrm{Cr}}(0) \frac{t}{\tau_{\mathrm{F}}}+N_{\mathrm{Nd}}(0)\right\}
\end{aligned}
$$

が得られる。ただし， $N_{\mathrm{Nd}}(0) ， N_{\mathrm{Cr}}(0)$ はそれぞれの初期 值であり，その比はNRとなる。

まず，蛍光特性の時間依存性について考える. Fig. 4 に $B_{2} / A_{2}$ をパラメータにしたときの計算結果を示す。た

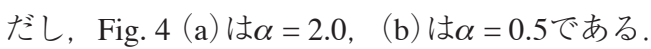

$\left|A_{2}\right|<\left|B_{2}\right|$ の場合, 最初はCrからの供給が $\mathrm{Nd}$ の自然放 出より多いため, 数密度が上昇するが, その後逆転し, 減少に転じる。さらに $\alpha>1$ の場合は, 減衰傾向はNd単 体のものよりも緩やかになる。逆に $\alpha<1$ の場合は， $\mathrm{Nd}$ の蛍光寿命が支配的となる。 $\left|B_{2} / A_{2}\right|$ が大きくなると数 密度の上昇割合も大きくなり, 上昇する時間幅も長くな る.このとき, 同じ $\left|B_{2} / A_{2}\right|$ の值に対して, $\alpha<1$ の方が 最大值は大きくなるが, 上昇する時間幅は $\alpha>1$ の方が
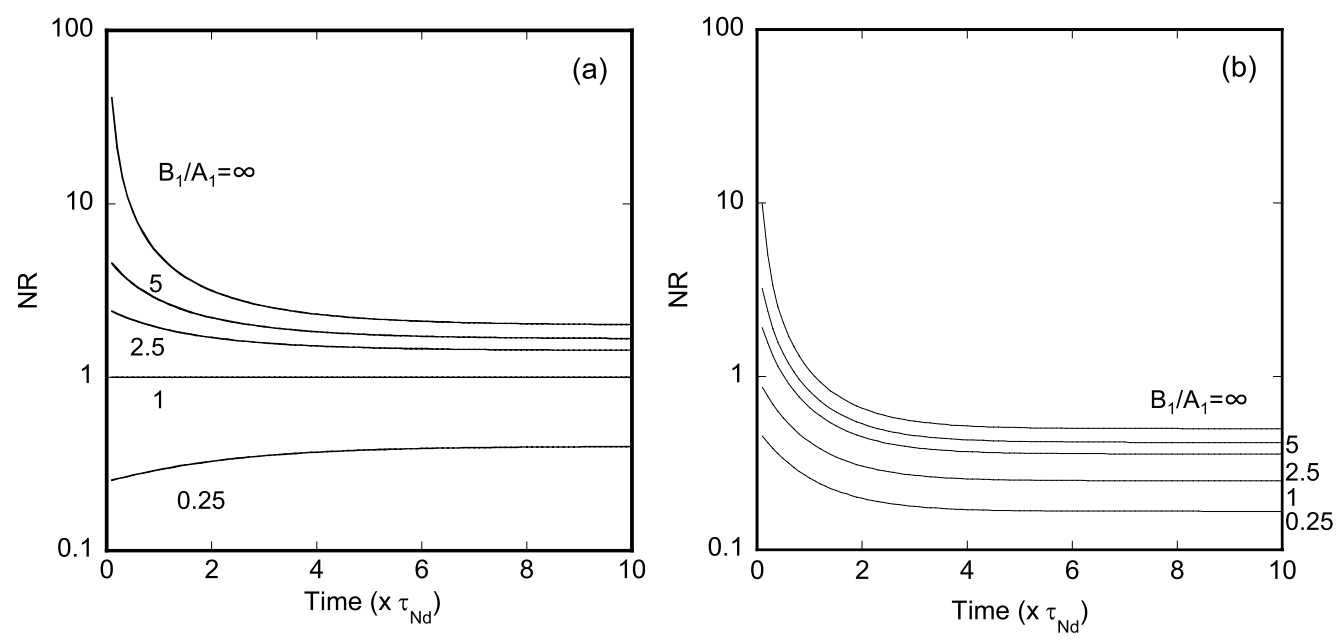

Fig. 3 Ratio of the populations of the upper $\mathrm{Cr}^{3+}$ and $\mathrm{Nd}^{3+}$ levels. 

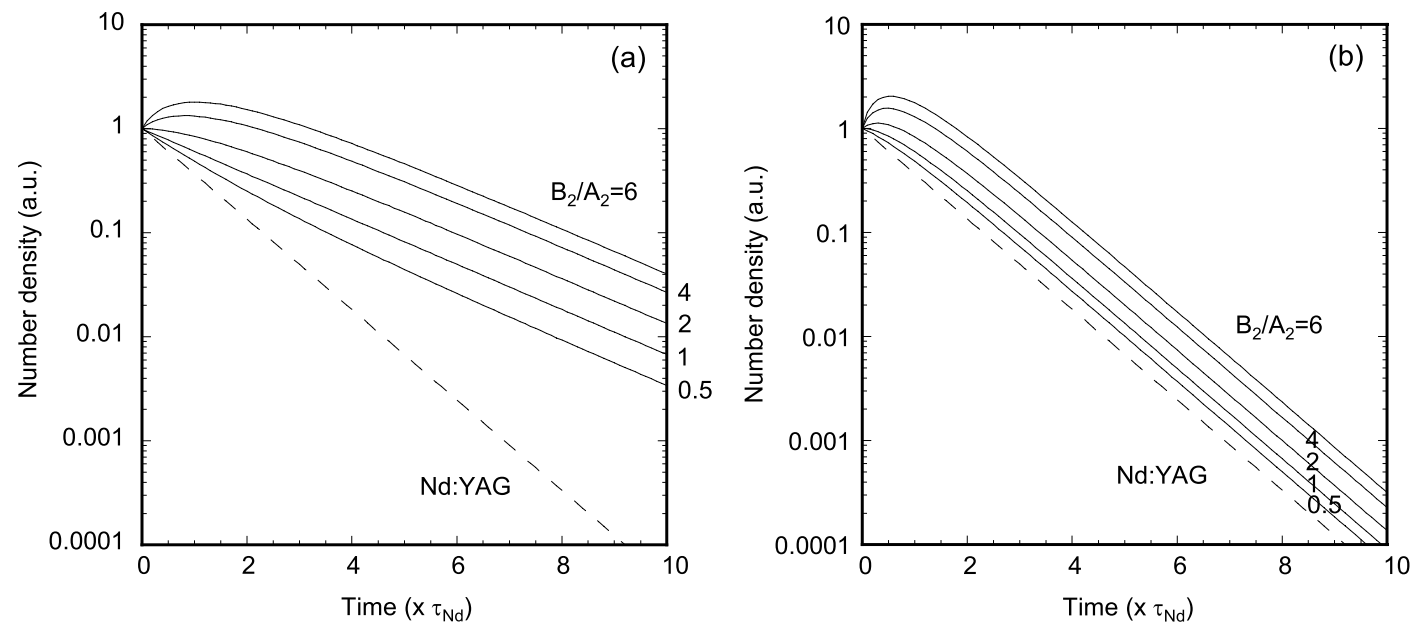

Fig. 4 Temporal profiles of the fluorescence from $\mathrm{Nd}^{3+}$ ions. (a) $\alpha=2.0$. (b) $\alpha=0.5$.

長い. このような数密度が上昇する現象は, 利得のピー クが励起終了時から遅れて現れることを意味している。 前章で述べたように, 初期数密度の比は励起時間が短い 場合や， Crの吸収帯のみで励起した場合などは非常に大 きな值をとるため, 利得のピークが励起パルスよりも大 きく遅れることになる，利得が最大となる時間を計算す るために，式(10)を時間 $t$ で微分する.

$$
\begin{aligned}
\frac{d N_{\mathrm{Nd}}}{d t}= & \frac{1}{\tau_{\mathrm{Nd}}} \exp \left(-\frac{t}{\tau_{\mathrm{Nd}}}\right)\left[-N_{\mathrm{Nd}}(0)+\frac{\gamma}{\alpha-1} N_{\mathrm{Cr}}(0)\right. \\
& \left.-\frac{\gamma}{\alpha(\alpha-1)} N_{\mathrm{Cr}}(0) \exp \left\{\left(1-\frac{1}{\alpha}\right) \frac{t}{\tau_{\mathrm{Nd}}}\right\}\right]
\end{aligned}
$$

式(12)において $\frac{d N_{\mathrm{Nd}}}{d t}=0$ とし, $t$ について解くと,

$$
t=\frac{\alpha}{\alpha-1} \tau_{\mathrm{Nd}} \ln \alpha\left\{1-\frac{\alpha-1}{\gamma N R}\right\}
$$

が得られる. 式(13)より，t>0においてピークを持つた めには,

$$
1<\alpha<\gamma N R
$$

または

$$
\gamma N R<\alpha<1
$$

が成立する必要がある

$A_{2}>B_{2}$ および, $\alpha>1$ の場合, 速い緩和と遅い緩和が 現れるbi-exponential となり, 比較的単純な減少傾向を示 す. $\alpha<1$ の場合, 初期はCrからの供給で減衰量が減る が，その後はNdの蛍光寿命が支配的となる.

次にNdの実効的な蛍光寿命について考える. $\alpha<1$ の 場合, Fig. 4（b）からわかるように, Ndの実効的な蛍光 寿命はNd:YAGの蛍光寿命とほとんどかわらない. $\alpha>1$ の場合は, $\mathrm{Cr}$ からのネルギー移譲の状況により大きく 変化する. 式(10)の右辺第1項が正の場合 $\left(A_{2}>B_{2}\right)$, 通 常のbi-exponential となり, その蛍光寿命は, 平均蛍光寿 命により近似可能である。平均蛍光寿命は,

$$
\left\langle\tau_{\mathrm{Nd}}^{\prime}\right\rangle=\frac{\left(A_{2}-B_{2}\right) \tau_{\mathrm{Nd}}^{2}+B_{2} \tau_{\mathrm{Cr}}^{\prime 2}}{\left(A_{2}-B_{2}\right) \tau_{\mathrm{Nd}}+B_{2} \tau_{\mathrm{Cr}}^{\prime}}
$$

$$
=\frac{1+\left(\alpha^{2}-1\right) \frac{B_{2}}{A_{2}}}{1+(\alpha-1) \frac{B_{2}}{A_{2}}} \tau_{\mathrm{Nd}}
$$

で計算することができる. Fig. 5 は $\tau_{\mathrm{Cr}}^{\prime}$ 経過後の波形に対 してmono-exponentialでフィッティングしたときの寿命 をプロットしたものである。曲線は式(16)で計算した。

縦軸はNdの本来の寿命で規格化し, 横軸は初期数密度 の比 $B_{2} / A_{2}$ である。 また, $\tau_{\mathrm{Cr}}^{\prime}$ と $\tau_{\mathrm{Nd}}$ の比 $\alpha$ を $1.2 \sim 3.0$ まで変 化させた。初期数密度の比が 1 以下の場合, 実効的な $\mathrm{Nd}$ の寿命は式(16)によく一致しており， $B_{2} / A_{2}$ に対する変 化が大きい傾向がある。しかし， $B_{2} / A_{2}$ が大きくなるに つれ，式(16)で計算された值よりも小さくなり，一定值 に落ち着く. $B_{2} / A_{2}$ が1より大きい場合には, mono-exponentialでのフィッティングは, 波形のどの部分から始め るかで值が変化しやすい. $B_{2} / A_{2}$ が1以下なら平均蛍光寿

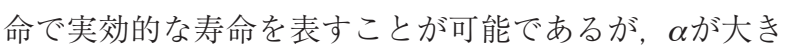
く, $B_{2} / A_{2}$ が1以上なら, 式(10)を使った方が良いと思わ れる. 特に, $B_{2} \gg A_{2}$ の場合, $A_{2}=0$ と見なせるので, 減 衰曲線は

$$
\exp \left(-\frac{t}{\alpha \tau_{\mathrm{Nd}}}\right)-\exp \left(-\frac{t}{\tau_{\mathrm{Nd}}}\right)
$$

に従うことになる．

\section{4. 蛍光寿命の濃度依存性と励起波長依存性}

これまでの考察を元にして参考文献2)の計測データを 解析してみる。参考文献2)では， Crの濃度が異なる3 種 類のサンプルを, 励起波長 $440 \mathrm{~nm}$ および590 nm, パル ス幅10 $\mu \mathrm{s}$ 以下で励起したときの波長1064 nmにおける実 効的な蛍光寿命を計測している. Table 1に参考文献2)の 結果を示す。この表から3つのことが読み取れる。(1)励 起波長 $440 \mathrm{~nm}$ の場合, つまり, Crのみを励起した場合 にはCr濃度が増加するにつれNdの寿命が短くなってい る。（2）励起波長590 nmの場合, つまり, Crと Ndを同時 に励起した場合にはCr濃度の増加により $\mathrm{Nd}$ 寿命が長 


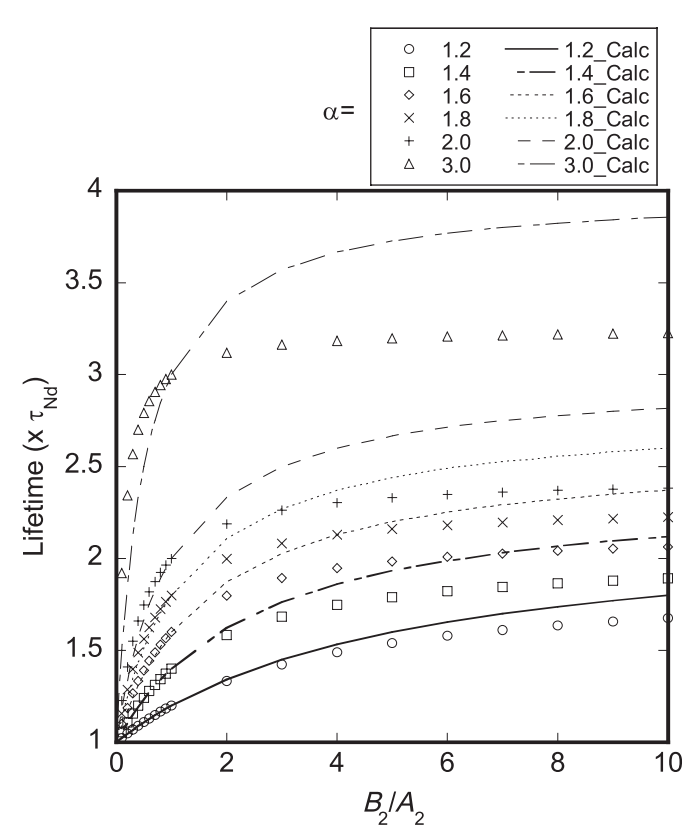

Fig. 5 Effective lifetime of the fluorescence from $\mathrm{Nd}^{3+}$ ions. These are fitted by mono-exponential equation. The solid lines are calculated by the equation of the averaged fluorescence lifetime.

くなる。（3）Crのみの励起とCrと Ndを同時に励起した場 合では同時に励起した方が $\mathrm{Nd}$ 寿命が短くなる。参考 のため, Fig. 6 (b)にNd:YAG とCr:YAGの吸収断面積を示 しておく.

まず，590 nm励起における計測值からNd単体での寿

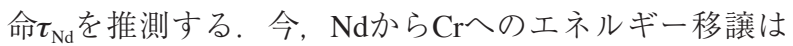
ないので, Cr濃度の違いによる影響を無視し，3種類の サンプルで同じ值をとると仮定する。 $\tau_{\mathrm{Nd}}$ の值は, $\mathrm{Cr}$ 濃 度0.1 at\%の計測值から $228 \mu \mathrm{s}$ 以下になっている可能性が 高い。また， $590 \mathrm{~nm}$ 付近にはNdの強い吸収があり, $\mathrm{Cr}$ 濃度をNdの3倍以上にしなければNdの励起レートの方が 大きくなる。このような場合, 数密度の比 $N R$ は 1 以下の 小さな值となる。したがって, 実効的な $\mathrm{Nd} の$ 寿命は式 （16）により近似できる。式(16)の中の $B_{2} / A_{2}$ を式(10)か ら計算すると，

$$
\frac{B_{2}}{A_{2}}=\frac{\gamma}{\alpha-1} N R(t)
$$

となる。 $N R(t)$ は式 $(8)$ で記述されている。 $A_{1}$ および $B_{1}$ は 励起レート， $\alpha, \gamma$, および $\mathrm{Nd}$ と $\mathrm{Cr}$ の寿命から計算でき る。また， $\gamma$ は， $\alpha$ おび $\mathrm{Nd}$ と $\mathrm{Cr}$ 寿命を使って，

$$
\gamma=1-\alpha \frac{\tau_{\mathrm{Nd}}}{\tau_{\mathrm{Cr}}}
$$

Table 1 Effective lifetime of Nd/Cr:YAG at $1064 \mathrm{~nm}$ measured by $\mathrm{H}$. Yagi, et al.

\begin{tabular}{|c|c|c|}
\hline 1 at $\% \mathrm{Nd}, 0.1$ at $\% \mathrm{Cr}$ & $732 \quad(\mu s)$ & 228 \\
\hline 1 at $\% \mathrm{Nd}, 0.7$ at $\% \mathrm{Cr}$ & 459 & 306 \\
\hline 1 at $\% \mathrm{Nd}, 3.0$ at $\% \mathrm{Cr}$ & 389 & 365 \\
\hline
\end{tabular}

Sample Pumped at $440 \mathrm{~nm}$ Pumped at $590 \mathrm{~nm}$

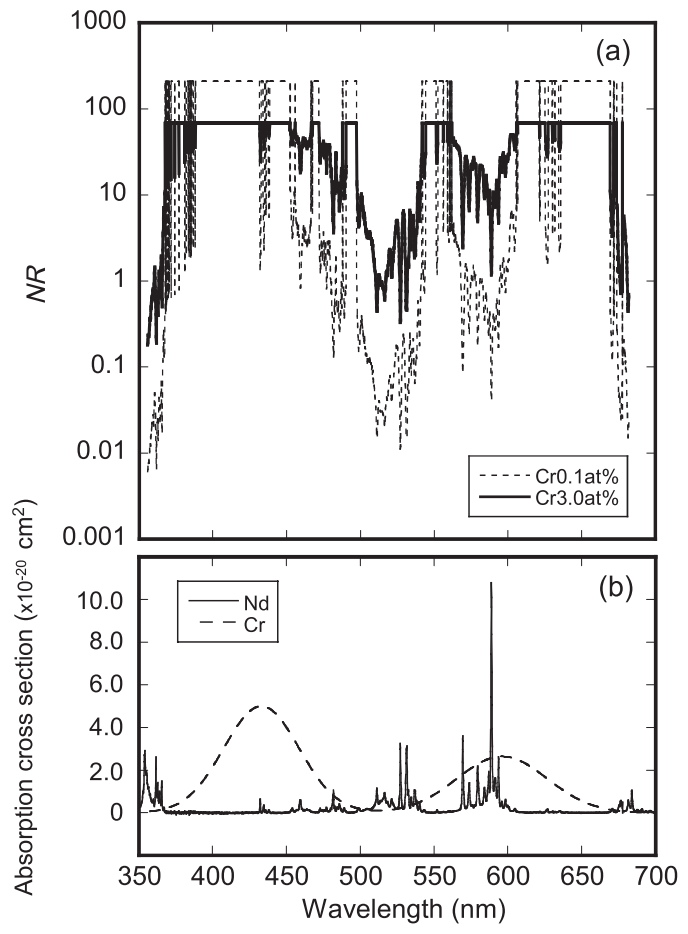

Fig. 6 (a) Wavelength dependence of the number density ratio, $N R$. (b) Absorption cross section of Nd:YAG and $\mathrm{Cr}^{3+}$ :YAG medium.

となる。したがって，式(8)，（16），(18），および(19） を使うと, $\mathrm{Nd}$ の実効的な寿命は励起レート， $\alpha$, 励起時 間 $t$ およびNdとCrの寿命によって表すことができる. 今, $\mathrm{Cr}$ の自発光の寿命が, $\mathrm{Nd}$ 添加の影響を受けない とすれば, $\mathrm{Cr}^{3+}$ : YAGで計測した $\mathrm{Cr} の$ 寿命 $($ 約 $1.5 \mathrm{~ms} \sim$ $2.0 \mathrm{~ms})^{12)}$ と励起時間 $t$, および励起レートを代入でき, 最終的な式は $\mathrm{Nd}$ の寿命 $\tau_{\mathrm{Nd}}$ と $\alpha$ の関数となる。 $\tau_{\mathrm{Nd}}$ と $\alpha$ をパ ラメータとして計算した結果, $590 \mathrm{~nm}$ 励起における $\mathrm{Cr}$ 濃度依存性を満たすためには，少なくとも $\tau_{\mathrm{Nd}}$ は2 $210 \mu \mathrm{s}$ 以 下になると推測できる。

次に，濃度依存性と励起波長依存性を計算するため に， $\alpha$ を推測する。波長 $440 \mathrm{~nm}$ での励起では, $\mathrm{Cr}$ のみを 励起することから，NRは非常に大きな值となる。その ため, Ndの実効的な寿命は式(16)に従わず，飽和值に なる. Fig. 5の計算結果から, Cr濃度 0.1 at \%の時は $\alpha>3, \quad 0.7$ at $\%$ の 時は $\alpha \sim 1.8,3.0$ at\%の 時は $\alpha \sim 1.4$ ぐら いであると推測できる。推測した $\alpha$ と Fig. 6 (b)に示して いる吸収断面積を用いてNRを計算した。励起時間は $10 \mu \mathrm{s}$ とている。計算結果をFig. 6 (a)に示す。横軸は 波長であり，縦軸はNRである。 $\mathrm{Nd}$ の吸収がない波長域 ではCr濃度に関係なくNRは大きな值をとる。NRが大き くなると実効的な寿命はNRの変化によらず一定となる ことから，この領域での励起では寿命は波長依存性を持 たない.Cr濃度が3.0 at\%の場合，NRが1以下になるのは $520 \mathrm{~nm}$ 付近で, その他の領域では1以上となっている. $590 \mathrm{~nm}$ 付近ではNRが1に近く，440 nmによる励起よりも 寿命が短くなることが予測できる。ただ，Fig. 5に示し ているように， $\alpha=1.4$ の場合には実効的な寿命の変化は それほど大きくない。一方，Cr濃度が0.1 at \%の場合は， 
$\mathrm{Nd}$ の吸収が存在する波長域でNRが大きく変化し，1以下 となる領域が多いことがわかる。ささらに， $\alpha$ の值も大き いと考えられることから, 実効的な寿命は励起波長に よって大きく変化する可能性が高い. $590 \mathrm{~nm}$ 付近での 励起ではNRは 0.1 以下となり, 実効的な寿命は $\mathrm{Nd} の$ 本来 の寿命に近い值となる.

これらの検討は励起時間 $10 \mu \mathrm{s}$ の時のものであるが， 十分に長い励起時間で励起した時はNRの波長依存性は 小さくなる。

\section{5. $\mathrm{Nd} / \mathrm{Cr}: Y A G の$ 蛍光寿命計測}

$\mathrm{Nd} / \mathrm{Cr}$ : $\mathrm{YAG}$ の蛍光は, 励起波長や $\mathrm{Cr}, \mathrm{Nd}$ の励起レー 卜，励起パルス幅，などの影響を受けて複雑な振る舞い をみせると考えられる。しかし，すべての要因は， Crか ら $\mathrm{Nd}$ のエネルギー移譲である。エネルギー移譲を特 徵づけるパラメータであるて も予測可能となる。 $\tau_{\mathrm{F}}$ を計測するためには，2段階のス テップを踏む必要がある。まず， Nd本来の寿命を計測 するために, Ndのみに吸収される波長で励起を行う。 このとき, 励起時間は任意でよい. この励起での蛍光の 減衰は単純なmono-exponential となるから $\tau_{\mathrm{Nd}}$ を容易に計 算できる。次に， $\alpha$ を特定するためにCrのみに吸収され る波長で励起を行う。このときの励起時間は反転分布が 定常状態になるまで行う必要がある，定常状態でのNR は式(9)となるが, 今, $\mathrm{Nd}$ の励起レートは零なので, $N R$ は $\alpha / \gamma$ となり， $B_{2}$ は $\alpha$ と $A_{2}$ で書き換えることができる。 し たがって，蛍光の減衰曲線を式(10)によりフィッティン

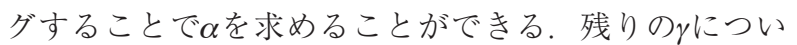
ては, Nd/Cr:YAG媒質のみから求めることは困難であ る。一つは, $\mathrm{Cr}^{3+}$ : $\mathrm{YAG}$ 使って $\tau_{\mathrm{Cr}}$ を計測しておく方法が

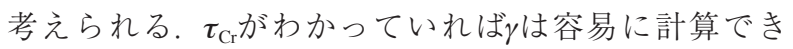
る。もう一つはNd:YAGと Nd/Cr:YAGの吸収断面積を計 測し， NdとCrの励起レートを明らかにしておくことで 可能となる。励起レートの比がわかれば, $\mathrm{Nd}$ と Crの両 方を励起できる波長で十分な時間励起すれば式(9), (10)から $\gamma$ を計算することが可能である.

\section{6. まとめ}

$\mathrm{Nd} / \mathrm{Cr}$ : YAG媒質の蛍光と励起の特性についてレート方 程式を使って解析した。 $\mathrm{Cr}$ 添加による Ndの反転分布の 上昇量は，エネルギー移譲率と $\mathrm{Cr}$ の励起レートによって 決まるが, 励起開始直後の $\tau_{\mathrm{Nd}}$ よりも短い時間では効果 が現れない。

$\mathrm{Cr}$ と $\mathrm{Nd}$ の数密度の比 $N R$ は, $\mathrm{Cr}$ の吸収帯域のみを励起 するような場合には極端に大きな值をとる可能性がある
が，十分に長い時間が経過した後は，一定值となる。蛍 光は, $N R$ が大きくなればなるほど, 発光のピークが励 起終了時刻よりも遅れて現れる。つまり，利得が最大と なる時間が励起パルスからずれることを意味しており， 増幅器を構成する場合には十分に考慮する必要がある.

蛍光寿命の測定において，実効的な $\mathrm{Nd}$ の寿命を測る のは難しいといえる。 $\mathrm{Nd}$ の実効的な蛍光寿命は，NRに 依存しており，NRが1よりも小さい場合には, mono-exponentialによるカーブフィットにより求めることができ るが，NRが1以上ではフィッティングの仕方によって変 化する可能性がある。

$\mathrm{Nd}$ の実効的な寿命は，励起波長に対する依存性をも つ。特にCr濃度が低い場合には顕著となり， $\mathrm{Nd}$ の吸収 が存在する波長域で寿命が短くなる。 $\mathrm{Cr}$ の濃度が濃くな ると，励起波長にあまり依存しなくなる。

Nd/Cr:YAG媒質を特徵づける重要なパラメータは, $\mathrm{Cr}$ から $\mathrm{Nd}$ のエネルギー移譲の寿命 $\tau_{\mathrm{F}}$ である。これは, 䄈が既にわかっているなら，Crのみを励起した場合の 発光特性およびNdのみを励起した場合の発光特性を計 測し, 式(9), 式(10)から, 反転分布の状況によらずに 求めることが可能である.

\section{参考文献}

1) A. Ikesue, K. Kamata, and K. Yoshida: J. Am. Ceramic Soc. 78 (1995) 2545

2) H. Yagi, T. Yanagitani, H. Yoshida, M. Nakatsuka, and K. Ueda: Opt. and Laser Technol. 39 (2007) 1295.

3) H. Okada, H. Yoshida, K. Sumimura, H. Fujita, and M. Nakatsuka: Conference on Lasers and Electro-Optics/Quantum Electronics and Laser Science Conference and Photonic Applications Systems Technologies, Technical Digest (CD) (Optical Society of America, 2006), paper CTuEE6.

4）佐伯拓, 今崎一夫, 本越伸二, 内田成明, 藤田尚徳, 中塚正大, 井澤靖和, 山中千代衛：レーザー研究 34 (2006) 374.

5) T. Saiki, K. Imasaki, S. Motokoshi, C. Yamanaka, H. Fujita, M. Nakatsuka, and Y. Izawa: Opt. Commun. 268 (2006) 155.

6) T. Saiki, S. Motokoshi, K. Imasaki, H. Fujita, M. Nakatsuka, and C. Yamanaka: Jpn. J. Appl. Phys. 46 (2007) 156.

7) T. Saiki, S. Motokoshi, K. Imasaki, K. Fujioka, H. Fujita, M. Nakatsuka, and C. Yamanaka: Opt. Commun. 282 (2009) 936.

8) T. Saiki, S. Motokoshi, K. Imasaki, K. Fujioka, H. Yoshida, H. Fujita, M. Nakatsuka, and C. Yamanaka: Opt. Commun. 282 (2009) 1358.

9) T. Yabe, T. Ohkubo, S. Uchida, K. Yoshida, M. Nakatsuka, T. Funatsu, A. Mabuti, A. Oyama, K. Nakagawa, T. Oishi, K. Daito, B. Behgol, Y. Nakayama, M. Yoshida, S. Motokoshi, Y. Sato, and C. Baasandash: Appl. Phys. Lett. 90 (2007) 261120.

10) T. Saiki, S. Motokoshi, K. Imasaki, K. Fujioka, H. Fujita, M. Nakatsuka, Y. Izawa, and C. Yamanaka: Jpn. J. Appl. Phys. 47 (2008) 7896.

11) Z. J. Kiss and R. C. Duncan: Appl. Phys. Lett. 5 (1964) 200.

12) K. Fujioka, T. Saiki, S. Motokoshi, Y. Fujimoto, H. Fujita, and M. Nakatsuka: J. Luminescence, submitted. 